\title{
A MULTI-ACTOR, MULTI-CRITERIA APPROACH FOR TECHNOLOGY SELECTION WHEN DESIGNING MOBILE INFORMATION SYSTEMS
}

\author{
Jan Ondrus ${ }^{1}$, Tung Bui ${ }^{2}$, and Yves Pigneur ${ }^{1}$ \\ ${ }^{1}$ University of Lausanne, Switzerland; ${ }^{2}$ University of Hawaii at Manoa, USA
}

\begin{abstract}
The fast ever-growing number of newly introduced mobile technologies makes the development of mobile information systems a somewhat complex activity. Decision makers - providers, merchants, and consumers alike - have to face great uncertainty and complexity regarding the acceptance of mobile technologies. Therefore, we stress that the selection process of an enabling technology for mobile commerce should be preceded with the use of a structured assessment methodology. With different available alternatives and various criteria for technology evaluation, multi-criteria decision making methods seem to be appropriate to support this selection process. Moreover, the success of introducing a new technology in a mobile information system depends on the preferences of varied involved actors in the market. We also consider in our approach the existence of multiple actors for the search of a technological consensus. As an illustration, we apply our approach to the mobile payment industry.
\end{abstract}

Keywords: Technology selection, multi-criteria decision making methods, Electre, mobile payments

\section{INTRODUCTION}

The widespread adoption of mobile devices has paved the way for the development of many innovative applications. However, the design of such applications or mobile information systems raises critical technical as well as business issues. This is partly due to the uncertainty surrounding the anticipated success or failure of enabling technologies. The traditional software and requirements engineering concepts, tools, and methods for 
analyzing, designing, and implementing mobile information systems are the essential perspectives of this workshop. The choice of the appropriate enabling technologies is key and has to be considered during the design process.

For example, in the transportation industry, a mobile information system would integrate various mobile services. One of them is the mobile payment system. During its development phase, the IS designers have to consider different technologies with a great amount of uncertainty. They have the choice between card-based and phone-based solutions. Apart from the physical form of the device, they also have to appraise the applicability of the possible embedded technologies in each device. In other words, RFID contactless cards are limited to physical transactions whereas mobile phones using SMS enable both physical and remote transactions. Moreover, for comparison purposes, they have to conduct an evaluation of various technological aspects such as the cost, the ease of use, and the security.

Thus, there seems to be a need for a more structured approach to support these types of evaluations and decisions. We contend that multi-criteria decision making (MCDM) approaches are well adapted for the problem at hand. MCDM methods imply a modeling activity, which should clarify many aspects, making the decision process more transparent. Moreover, Stewart considers MCDM to be largely concerned with the deployment of systematic methods to help address problems characterized by incomparable objectives, multiple stakeholders and conflicting interests (Stewart, 1992). Consequently, MCDM methods seem to be appropriate for technology selection in a multi-actor context where technological consensus is vital for success.

The objective of the paper is to illustrate the feasibility of using MCDM methods to select enabling technologies in the design process or mobile information systems. This paper is structured as follows: in Section 2, we briefly discuss the potential of MCDM methods for technology assessment. In Section 3, we present a MCDM procedure for the technology selection, using a well-known technique of preferences aggregation with first insights into the mobile payment industry. Finally, in Section 4, we conclude with a summary.

\section{MCDM FOR TECHNOLOGY ASSESSMENT}

Multiple criteria decision methods, in general, have proven useful in supporting decision making (Keen, 1977; Zeleny, 1982). Few attempts were made to assess technologies with MCDM methods. Chan et. al propose to use fuzzy MCDM method to determine best technology selection. They 
present a systematic approach using the concept of fuzzy set theory and hierarchical structure analysis to help decision makers to make suitable decisions in uncertain environments (Chan et. al, 2000). Salo et al. suggest the use of MCDM for technology foresight. They argue that there is a potential "in terms of lending rigor and transparency to foresight process" (Salo et al., 2003). Chou et al. tried to apply a multi-criteria decision making, such as AHP (Saaty, 1980), to assess mobile payment (Chou, et al., 2004). They analyze and explain the performance of different current payment instruments with technological, economic, and social factors. Their objective was to use these different factors in order to explain success or failures. One motivation of this analysis is that a payment system: "can be flawed technologically but still become the de facto e-payment scheme due to the advantage of an established customer base" (e.g. Chou, et al., 2004).

\section{MCDM PROCEDURE FOR TECHNOLOGY SELECTION}

In this section, we outline the basic steps used in MCDM as they apply to the technology selection. It consists of the following steps:

1. Definition of the problem and its alternative solutions

2. Identification of the stakeholders

3. Definition of selection criteria

4. Selection of the technique of preferences aggregation

5. Evaluation of solutions in respect to each selection criterion

6. Search for consensual solution

To illustrate the MCDM approach, we use the mobile payment industry as the running example. In the light of the many past mobile payment system failures, we consider this market to be an interesting case study for our illustration. Moreover, we assume that there is a real need to analyze and compare the different technologies using a more structured approach. There are also various important actors to include in our model. The propose analysis is just for illustration purposes. The data that are used for this analysis are derived from an extensive research in the literature, from opinions of few experts, and also from interviews conducted in Switzerland for the purpose of a previous published research. This was done as first data inputs to run the model in order to evaluate the pertinence of MCDM method for assessing the mobile payment market.

Definition of the problem and its alternative solutions. With the continuous growth of the mobile industry, a variety of wireless technologies emerged in order to enable new mobile products and services. Some of them 
could be well used for mobile payment services. However, these technologies differ not only in their capabilities but also in the impact they have on the different stakeholders. For the purpose of this paper, we selected three technologies that are known to be leading candidates for mobile payments. The first alternative is the contactless card embedded with a RFID (Radio Frequency Identification) tag. These cards tend to become very popular for many reasons. They are cheap, reliable, and very easy to use. Then, we chose mobile phones using proximity networks such as Bluetooth, RFID, and Infrared. This solution is good for proximity payment in the real world. Finally, we included mobile phone using remote networks (e.g. GSM, GPRS, UTMS, EDGE, WLAN). These devices are suitable for remote payments such as e/m-commerce transactions. Each of the introduced technologies has its advantages and drawbacks. Some have limitations that others do not have. For that reason, a mobile payment service provider should consider all these options before launching a scheme. For benchmarking purposes, we also included two very popular payment technologies such as magnetic cards (e.g. VISA, Mastercard) and smartcards (e.g. Proton). This will help us not only to compare the new mobile with the existing technologies but also give us good insights about the current market.

Table 1. The Technologies Selected for the Mobile Payment Case

\begin{tabular}{ll}
\hline Technolegy & Example \\
\hline Conctactless card (RFID tag) & Octopus (Hong Kong) \\
Mobile phone "proximity" (Bluetooth, RFID, Infrared) & Moneta (South Korea) \\
Mobile phone "remote" (GSM, GPRS, etc) & Paybox (Austria) \\
Magnetic card & Visa, Mastercard (Worldwide) \\
Smartcard & Proton (Belgium) \\
\hline
\end{tabular}

Identification of the stakeholders. As there are varicus identified stakeholders in the mobile payment industry, we classified them in different groups. We distinguish actors involved in mobile payment trânsactions directly (players) and indirectly (rilers). The rulers set a legal framework (regulators) by making rules and controlling others' obedience, while there are also diverse actors (technology suppliers) in charge of providing the technology to the players. On their side, the players represent the demand (merchants and consumers) and the supply (mobile payment service providers). For our research, we choose to include only the players as they are very important since the success of a mobile payment scheme necessarily depends on their adoption. Moreover, they must be convinced about a technological consensus in order to enhance the success of a particular solution.

For our analysis, we formed three stakeholder groups: provider, merchant, and consumer. We assume that there is a general consensus about the issues they individually worry about. Indeed, all the merchants agree 
with each other. They are all part of the same group. The same assumption has been made with the other stakeholders.

Definition of selection criteria. Criteria are used to capture the points of view that decision-makers use as a frame for reference in their selection process. Criteria should be comprehensive in that when taken all together, they should be able to represent a rather complete perspective of the user with regard to the problem. Table 2 summarizes the criteria adopted by each of the three groups of stakeholders in the selection of mobile payment technologies. Due to space constraints, we just provide the list of the stakeholders criteria used for our case. They are derived from the literature.

Table 2. List of the stakeholders' criteria

\begin{tabular}{lll}
\hline Provider & Merchant & Consumers \\
\hline Cost & Cost & Cost \\
Organizational change & Customer base & Ease of use \\
Security & Ease of use & Expressiveness \\
Standard & Reliability & Trust \\
& Security & Universality \\
& Value proposition improvement & Usefulness \\
\hline
\end{tabular}

Selection of the technique of preferences aggregation. As discussed earlier, MCDM allow analysis of several criteria simultaneously or concurrently. These criteria may be either quantifiable (e.g. cost, speed, etc) or non-quantifiable (e.g. quality of service, esthetics, etc). More importantly, at least from the decision-maker viewpoint, the multiple objectives often work against each other. The improvement or achievement of one criterion can be accomplished only at the expense of other.

MCDM also allow consideration of the decision-maker subjective evaluation which is often crucial in decision problems: In most MCDM, the decision-maker can express his/her preferences by weighting the evaluation criteria, making pairwise judgements or by simply giving an ordinal ranking of a subset of alternatives. The preference aggregation process can be algorithmically precise (e.g. multi-objective linear programming) or heuristic (e.g. spacial proximity). Quantitative or qualitative techniques such as simulation or scenario analysis can also be used as preliminary analysis prior to the use of a MCDM (Bui, 1987). Stewart (1992) and Salo et al. (2003) offer a review of some of the most popular MCDM techniques.

As an example of a technique of preferences aggregation, we chose ELECTRE I (Benayoun et al., 1966) for our mobile payment case. This approach allows the decision maker to select the ideal technology with a maximum of advantages and a minimum of inconveniences in the function of various criteria. ELECTRE I gives the possibility to model a decision making process by using the concordance and discordance indexes and the 
outranking relations. The concordance index measures the degree of dominance of one action over another, based on the relative importance weightings of the decision criteria. The discordance index measures the degree to which an action is worse than another. In summary, concordance and discordance indices can be viewed as measurements of satisfaction and dissatisfaction that a decision maker senses when choosing one action over another.

The outranking relations are usually obtained with a combination of a high level of concordance and a low level of discordance. These levels are fixed by a concordance and a discordance threshold which can be seen as severity levels over and under which an action could outrank another.

Based on relatively simple hypotheses, the objective of ELECTRE I is modest as it simply proposes a subset of alternatives (in our case, technologies) which definitely excludes the "best" solution. As a result, the decision maker has to be conscious that the kernel (i.e. the set of nondominated alternatives) includes not only the "best" solution but also all the alternatives that are hard to compare between each other.

Evaluation of solutions in respect to each selection criterion. The purpose here is to help the decision-maker express his preferences with regard to the possible solutions. This preference elicitation is made in respect to each of the criteria considered for the selection problem.

Table 3. Evaluation by the provider group (for illustration purpose)

\begin{tabular}{lcccccc}
\hline Criteria & Weight & $\begin{array}{c}\text { Magnetic } \\
\text { card }\end{array}$ & Smartcard & $\begin{array}{c}\text { Contactless } \\
\text { Card }\end{array}$ & $\begin{array}{c}\text { Mobile } \\
\text { phone } \\
\text { "remote" }\end{array}$ & $\begin{array}{c}\text { Mobile } \\
\text { phone } \\
\text { "proximity" }\end{array}$ \\
\hline Cost & $60 \%$ & 4 & 3 & 3 & 1 & 2 \\
Org. chan. & $10 \%$ & 3 & 3 & 3 & 1 & 1 \\
Security & $10 \%$ & 1 & 3 & 3 & 4 & 2 \\
Standard & $20 \%$ & 4 & 3 & 1 & 2 & 1 \\
& & $0=$ weak; 1 = fair; 2 = average; 3 = good; 4 = excellent. \\
\hline
\end{tabular}

Search for consensual solution. As previously claimed, a consensus between the major stakeholders of the market is desirable. As a result, the success probability of a global payment scheme based on a unanimous technology choice would be higher. Following this requirement, we had to use a group decision approach. Bui and Jarke (1984) have previously proposed a method based on ELECTRE I for group decision making. They suggested applying the min-max concept of game theory (von Neumann, 1953). In other words, to reach a consensus, this method takes the most severe technology evaluations for each criterion done by any actor. 
Concordance Matrix

\begin{tabular}{|l|c|c|c|c|c|} 
& $\begin{array}{c}\text { Magnetic } \\
\text { Card }\end{array}$ & Smartcard & $\begin{array}{c}\text { Contactless } \\
\text { Card }\end{array}$ & $\begin{array}{c}\text { Mobile phone } \\
\text { "Remote" }\end{array}$ & $\begin{array}{c}\text { Mobile phone } \\
\text { "Proximity" }\end{array}$ \\
\hline Magnetic card & - & 65 & 35 & 65 & 65 \\
Smartcard & 20 & - & 40 & $\mathbf{8 5}$ & $\mathbf{8 5}$ \\
Contactless card & 20 & 60 & - & 70 & $\mathbf{1 0 0}$ \\
Mobile phone "Remote" & 10 & 10 & 25 & - & - \\
Mobile phone "Proximity" & 10 & 0 & 20 & 65 & - \\
\hline
\end{tabular}

\section{Discordance Matrix}

\begin{tabular}{|l|c|c|c|c|c|} 
& $\begin{array}{c}\text { Magnetic } \\
\text { Card }\end{array}$ & Smartcard & $\begin{array}{c}\text { Contactiess } \\
\text { Card }\end{array}$ & $\begin{array}{c}\text { Mobile phone } \\
\text { "Remote" }\end{array}$ & $\begin{array}{c}\text { Mobile phone } \\
\text { "Proximity" }\end{array}$ \\
\hline Magnetic card & - & 56 & 63 & 67 & 44 \\
Smartcard & 22 & - & 33 & 13 & $\mathbf{1 3}$ \\
Contactless card & 70 & 60 & - & 40 & 0 \\
Mobile phone "Remote" & 78 & 56 & 63 & - & 33 \\
Mobile phone "Proximity" & 70 & 60 & 50 & 56 & - \\
\hline
\end{tabular}

\section{Outranking Matrix}

\begin{tabular}{|l|c|c|c|c|c|}
\multicolumn{1}{|c|}{$(\mathrm{P}=.75$ and $\mathrm{Q}=.25)$} & $\begin{array}{c}\text { Magnetic } \\
\text { Card }\end{array}$ & Smartcard & $\begin{array}{c}\text { Contactless } \\
\text { Card }\end{array}$ & $\begin{array}{c}\text { Mobile phone } \\
\text { "Remote" }\end{array}$ & $\begin{array}{c}\text { Mobile phone } \\
\text { "Proximity" }\end{array}$ \\
\hline Magnetic card & - & 0 & 0 & 0 & 0 \\
Smartcard & 0 & - & 0 & 1 & 1 \\
Contactless card & 0 & 0 & - & 0 & 1 \\
Mobile phone "Remote" & 0 & 0 & 0 & - & 0 \\
Mobile phone "Proximity" & 0 & 0 & 0 & 0 & - \\
\hline
\end{tabular}

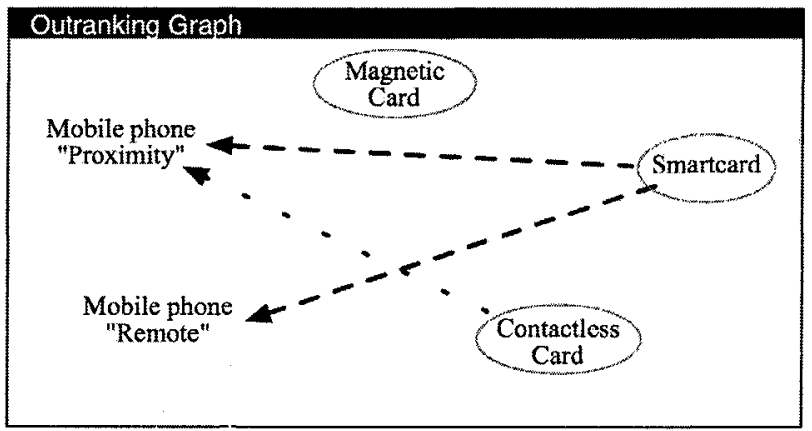

\section{Legend}

\section{Concordance matrix}

$100=$ All criterie favor the selection

$0=$ No criteria favor the selection

Discordance matrix

$0=$ No opposition to selection

$100=$ Total ooposition to selection

Outranking matrix

$\mathrm{C}=$ No outanking refation

$i=$ Outranking rilation

Outranking graph

A directed arrow shows that a

solution outranks the other

Figure 1. Group result (illustration)

\section{SUMMARY}

The use of MCDM for assessing the mobile payment market shows encouraging results. In fact, even with our first exploratory data inputs, we obtained interesting insights that are somewhat representative of the current market state.

The proposed methodology should improve the technology selection process as it allows consideration for multiple actors to express their 
personal preferences in the selection process. With the use of a DSS, we could perform sensitivity analysis and visualization of the outcome capabilities. DSS also present the possibility to conduct market simulations in order to build evolving scenarios.

In conclusion, we hope that using MCDM could be a key component for improving the development of successful mobile information systems, as the choice of technology is crucial.

A further research would be to apply this approach in a real setting and therefore, capture the stakeholders' preferences of the current market.

\section{ACKNOWLEDGEMENTS}

The work presented in this paper was supported by the National Competence Center in Research on Mobile Information and Communication Systems (NCCR MICS), a center supported by the Swiss National Science Foundation under grant number 5005-67322.

\section{References}

Benayoun, B. , Roy, B., and Sussmann, B. (1966). Manuel de reference du programme electre. Note de synthèse, formation n.25, Direction scientifique SEMA, Paris.

Bui, T. (1987). Co-oP: A Group Decision Support System for Cooperative Multiple Criteria Group Decision Making, volume 290 of Lecture Notes in Computer Science. SpringerVerlag, Berlin.

Bui, T., Jarke, M. (1984). A dss for cooperative multiple criteria group decision making. International Conference on Information Systems (ICIS)

Chou, Y., Lee, C., and Chung, J. (2004). Understanding m-commerce payment systems through the analytic hierarchy process. Journal of Business Research, 57, 12, 1423-1430.

Chan, F.T.S, Chan, M.H., and Tang, N.K.H. (2000). Evaluation methodologies for technology selection. Journal of Materials Processing Technology, 107, 330-337.

Keen, P.G.W. (1977). The involving concept of optimality. TIMS Studies in the Management Sciences, 6, 31-57.

Von Neumann J. and Morgenstern O. (1953). Theory of games and economic behavior, $3^{\text {rd }}$ Ed. Princeton University Press, Princeton, New Jersey.

Saaty, T. (1980). The analytic hierarchy process: planning, priority, allocation. McGraw-Hill Book Company, New York.

Salo, A., Gustafsson, T., and Ramanathan, R. (2003). Multicriteria methods for technology foresight. Journal of Forecasting, 22(2):235-255.

Stewart, TJ. (1992). A critical survey of the status of multiple criteria decision making theory and practice. OMEGA, 20, 569-586.

Zeleny, M. (1982). Multiple objective decision making. Addison-Wesley, Readying, Massachusetts. 